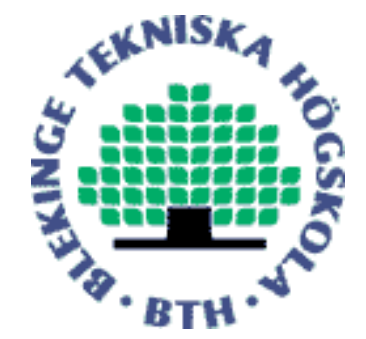

Copyright (C) 2010 IEEE.

Citation for the published paper:

Propositions for the expanded core competence model

Urban Ljungquist

ICMIT2010, International Conference on Management of Innovation and Technology

2010 Singapore

This material is posted here with permission of the IEEE. Such permission of the IEEE does not in any way imply IEEE endorsement of any of BTH's products or services Internal or personal use of this material is permitted. However, permission to reprint/republish this material for advertising or promotional purposes or for creating new collective works for resale or redistribution must be obtained from the IEEE by sending a blank email message to pubs-permissions@iee.org.

By choosing to view this document, you agree to all provisions of the copyright laws protecting it. 


\title{
Propositions for the Expanded Core Competence Model
}

\author{
U. Ljungquist \\ Department of Management, Blekinge Institute of Technology, Ronneby, Sweden \\ (ulj@bth.se)
}

\begin{abstract}
This conceptual paper advances our conceptions of core competence, going beyond mere identification. Drawing on existing theories, the paper proposes how the influences on a core competence can be managed by acknowledging the need for influence, and the applicability of associated concepts to satisfy that need. We also add a time continuum, wherein a company's shared history and shared future specific goals are highlighted, which could strengthen the influence on a core competence.

An expanded core competence model is proposed. The model suggests a more detailed, more comprehensive approach, applicable to core competence management issues by scholars and practitioners alike.
\end{abstract}

Keywords - Core competence, innovation, strategic development

\section{INTRODUCTION}

Core competence probably is one of the most important sources of company competitive advantage. In fact, the core competence is often said to be a steppingstone to future corporate success, for example, in developing innovation processes. Despite its importance, the concept has yet to be completely explored, conceptually or empirically. This paper draws on the existing literature and proposes two dimensions (time continuum and link characteristics) that supplement our understanding of the core competence concept.

The great hopes for core competence as a general source of future company success have unfortunately resulted in the application of the concept without focused and thorough analysis. Although the concept has been on the agendas of scholars, consultants, and managers for over 20 years, our understanding of it still is limited, as has been recognized by several scholars [1-3]. One reason for this is the lack of conceptual and empirical studies clarifying the details of the core competence concept, its characteristics, context, etc. [4, 5].

One example of an overlooked analytical focus is corporate history, in which sequences of core competence development might be discovered and in which a vast amount of understanding might hide. Understanding its own history is critical for any company, as it enables, for example, the identification and acknowledgement of impeding trajectories, such as path dependency $[6,7]$, that could influence future development. Put differently, a company's current success may depend on historic processes [8, 9].

For core competence issues, understanding firm history is also important for practical reasons, since the today's products exist because of previous investments in core competencies. Neglecting to make the necessary investments is known as the "innovators dilemma" [10], which has also been studied empirically [e.g. 11].

A line of thought is easily extended from the pastpresent continuum to the present-future continuum. From that perspective, scholars conclude that a company's future success and products result from investments in the core competencies of today [12]. This history- (path-) dependent notion of core competence, linking, for example, the products of today with yesterday's core competencies, has not been fully researched. This paper acknowledges and addresses our incomplete understanding of these matters.

Furthermore, despite a vast amount of literature on core competencies [e.g. 4, 13], our understanding of how core competencies are influenced currently is lacking. One reason is an overwhelming concentration on core competence identification, another is that the identification processes per se is over-simplified [for a review, see e.g. 4]. For example, three concepts are agreed to be associated with core competence, namely, capability and resource [e.g. 13, 14]. These three "associated concepts" are clustered and often interchangeably defined. In fact, they are regularly only used in the core competence identification process, i.e. in "funnelling" a core competence. This clustering might be advantageous in a straightforward identification process, but it hampers the detailed understanding of the core competence concept - which should be inherent in a detailed understanding of the associated concepts.

In this paper, we attempt to advance our understanding of the core competence concept, going beyond merely identifying it, while simultaneously trying to avoid simplification when exploring how core competencies are influenced. 
An empirical study was designed to deal with the challenges of studying how the core competence is influenced. The findings indicate, first, that the associated concepts (i.e. competence, capability, and resources) have different characteristics, all of which could influence a core competence, which implies that they are linked (conceptually and/or empirically verified) to the core competence. For example, a customer management system (empirically categorized as a capability) was found in the empirical study to have influenced (bringing structure to the development) a core competence. The findings also suggest that these links also could differ in strength, which implies that they are dynamic and complex. Furthermore, a link could become obsolete for various reasons, in that the link between an associated concept and a core competence could collapse. Thus, the links seem just as crucial as the associated concepts themselves in transferring the characteristics of the latter to a core competence. We can conclude that these links are critical and must be acknowledged and understood.

To sum up, this paper advances the core competence concept, going beyond straightforward processes of identification, to propose an expanded core competence model.

\section{THEORY}

Its initiators defined the core competence concept as "the collective learning in the organization, especially how to coordinate diverse production skills and integrate multiple streams of technologies" [15:82]. The vagueness of this definition has made its empirical operationalization problematic $[1,2]$. For that reason, a core competence is not defined here using that definition, but as a competence fulfilling three criteria suggested by the concept's initiators $[15,16]$ :

1) a core competence must contribute significantly to customer benefit from a product;

2) a core competence should be competitively unique and, as such, must be difficult for competitors to imitate, and

3) a core competence should provide potential access to a wide variety of markets.

Using these criteria to define what constitutes a core competence has several benefits: they refer to the original definition $[15,16]$ and suggest that core competence is not an isolated concept, since it is conceptually linked to that of competence. In other words, to identify a core competence empirically, a competence first must be identified.

Competence is not the only concept commonly used in empirically identifying core competence. As previously is mentioned, two more concepts are also agreed to be associated with core competence, namely, capability and resource.

There are nearly as many definitions of the associated concepts as there are scholars using them. This poses a major problem in practice (e.g. when operationalizing), namely, that of determining which definition is most accurate and applicable. This dilemma has recently veen emphasized by scholars [17]. In the present paper, the associated concept definitions are not the focus. Nevertheless, we present a summarized review here; a fuller review of the various alternative definitions - both conceptual and for operationalization - is found elsewhere [e.g. 4].

Researchers have identified various types of competencies related to product development: first-order, which comprise customer and technological competencies; integrative, which is the ability to combine the previous type; and second-order, which is the ability to build first-order competencies [e.g. 18]. Integrative competencies and the like are also examined in knowledge-based theory [19]. Other scholars have defined competence as "the ability to sustain the coordinated deployment of assets in ways that help a firm achieve its goals" [20]. Competence is often referred to as something that aims to develop and refine, as implied above. Accordingly, in this paper, we define competence as knowledge, situated in individuals and teams, that aims to cause improvement.

Capability is tangible or intangible; it is firm specific and created over time through interaction between resources [21] or strategically understood business processes [22]. It is also a mixture of routines, tacit knowledge, and organizational memory [9]. Scholars have separated capabilities into operational and dynamic capabilities [23-25]. As the reader may have discerned, capability is used in many ways [see also 26]. In the present paper, capability is defined as a system or routine that supports the process and activity of coordination and integration.

Resources are one of the most basic attributes of a company - and are therefore natural objects of study since they are inputs to a company's value process [23, 27]. Resources are identified as sources of sustainable competitive advantage if they are valuable, rare, inimitable, and organization-able [28]. Furthermore, resources can both hinder and ease organizational change via core capabilities and core rigidities [6]. Six classes of resources are suggested: financial, physical, human, technological, organizational, and reputation [27]. Adapted from the definitions above, this paper defines resources as inputs to the value process. 


\section{DISCUSSION}

The following section introduces factors that influence the strength of a link, and the ensuing discussion is developed into propositions. First, the link characteristics are discussed, then a time continuum is introduced as an analytical dimension.

\section{A. Link Characteristics}

It is generally true that a core competence is a source from which company performance and success grows, an understanding that links core competence downstream in the value chain to the other associated concepts. Core competence must, however, be continuously developed to remain a source of future success. As mentioned before, an empirical study has demonstrated that a competence improves, a capability supports, and a resource is input to a value process - when linked to a core competence. However, demand from (i.e. driven by) a core competence is a prerequisite condition, inferring a need for a particular associated concept. Thus, it is core competence demand that establishes the link between the core competence and an associated concept. The aforementioned empirical study cites the example of a core competence in need of structure in order to focus its ongoing developments and efforts. By treating top management vision (an empirically identified capability) as a guiding light, the activities, processes, etc. involved in the focal core competence could be allocated to bring about the required structure and concentration.

The demand from a core competence may be strong or weak, which implies weaker or stronger links. A weak link exists when a core competence has no need of a particular associated concept, for example, due to discontinuous technology developments. This no-need aspect calls for the close monitoring of the needs of a core competence. A strong link implies a greater need for a particular associated concept: i.e. a greater need for improvements (from a competence), or a greater need for supports (from a capability), or a greater need for input to the value chain (from a resource). One empirical example of a strong link is when a core competence involved in establishing new customer relations requires rapid development. A sales task force (an empirically identified competence) was set up to meet the need, so the core competence was influenced and developed. Accordingly, we suggest Proposition 1A: The stronger the need of a core competence for a particular associated concept, the stronger the link between the two.

Just as a core competence requires development, so do the associated concepts. The latter, if not continuously developed and refined in accordance with the focal core competence's need, might be unable to influence that core competence indefinitely, because it could become obsolete. This can happen when a competence cannot improve a core competence any further, for example, due to asset erosion [29] or technological disruption.

Furthermore, an associated concept not only must be up-to-date to be linked to a core competence's need, but must also be applicable to the focal core competence. An empirical example of an associated concept not being relevant to a core competence was when a company's top management team decided to invest in the company brand, including enhanced marketing efforts, with the overarching goal of leveraging the development of the core competence via its end products. The core competence, however, was in no need of such actions, which resulted in no actual development of the focal core competence. Thus, we suggest Proposition 1B: The stronger the applicability of an associated concept to a particular core competence's needs, the stronger the link between the two.

\section{B. Time Continuum}

An inherent aspect of the core competence concept is that investments in a core competence could be spent, not only on existing products, but also on future products which represent the end result of core competence investments [12]. Thus, the notion of core competence naturally invokes a time dimension, in this example, towards the future. Recent research into core competence, touching, for example, on the erosion of existing innovation paths, which is proposed opening up to development of new core competencies, also includes time as main analytical dimension [30]. Furthermore, companies often are managed and developed with the general aim of improving (future) performance [1, 28]. The core competence concept is well suited for this, and for other general company developments, by its capacity for improving processes [21, 23, 24] and inherent coordination and integration ability $[18,20]$. In fact, improvements and developments, as general company goals, are arguably inherent to the core competence notion.

Core competence could also be directed towards more specific goals, for example, fulfilling customers' future needs [31], thereby functioning as company strategy [32]. However, these goals, although company specific, are still part of our general understanding of core competence, i.e. inherent to the definition of the concept [15]. Goals specific to a particular core competence should be formulated in great detail, for example, to be competitive in a particular product development and to develop a new specified technology. An empirical example of a shared specific goal is when reorganizing the settings of a core competence - at risk of becoming redundant due to a 
dynamic environment. The changes include eliminating unneeded components (e.g. obsolete software and technologies) and reshaping excess capacities (in terms of resources, capabilities, and competencies) by adapting them to be able to form links to a new version of the potentially redundant core competence. This includes developing the outcomes of the core competence, such as end products, to meet the markets emergent demands. The core competence and associated concepts had all adopted the same specific goal, and accordingly shared the same focus in achieving the goal. A core competence can share both general and specific goals with any associated concept; however, a shared goal does not establish a link between the concepts per se. Thus, we suggest Proposition 2A: A core competence and an associated concept that share a future goal that is specific rather than general in nature will develop a strong link.

Links between a core competence and any of the associated concepts may not only be shared by a future goal, but also by a shared history. One scholar has identified upsides and downsides in sharing a history [6]. She suggests that core capabilities ease and core rigidities hinder future change and development, if the associated concepts are sticky (unchanging in the near future), fungible (interchangeable), path dependent (history bounded), and causally ambiguous (tacit, complex, and specific). Thus, a core competence previously linked to an associated concept may be hindered due to the time of its evolution. On the other hand, a shared history could hinder the (competitive) imitation of the focal associated concept due to time compression, diseconomies, asset mass efficiencies, interconnectedness of asset stocks, asset erosion, causal ambiguity, and substitution [29].

Thus, the sharing of a history by a core competence and any of the associated concepts implies both pros and cons. On one hand, the imitative protection enhances the firm's external competitiveness; on the other, core rigidities could internally hinder the same development. Accordingly, we may conclude that the sharing of a history by focal concepts does not necessarily mean straightforwardly enhanced competitive advantage. Hence, we need further arguments to be able to separate the upside examples of shared history from the downside examples.

In an empirical study, we found evidence that the associated concepts that remained linked to a core competence, even through major reorganizations of the core competence, helped maintain their links (i.e. exert a positive influence) with the core competence. The findings indicate that an ISO certificate (a capability), for example, even though only irregularly updated and therefore unlikely to meet the immediate needs of a core competence on a continuous basis, still helped maintain the core competence link. We also noted that the associated concepts that had developed proactively, i.e. that met a core competence's need before it was urgent, were successful in maintaining their links to the core competence. An empirical example of the latter is a software development team (a competence) that kept returning to a core competence in logistics solutions, suggesting improvements to end products not yet requested by customers. Thus, we suggest Proposition 2B: A core competence and an associated concept that share a history, when the associated concept either sustains the link during dynamic periods or proactively updates it, will develop a strong link.

\section{CONCLUSIONS}

This paper has proposed link characteristics and a time continuum concept that together expand existing conceptions of core competence. The conceptual discussion implies that previously overlooked factors may influence the link between associated concepts and core competence. Four propositions are presented in this paper. They are:

1A) The stronger the need of a core competence for a particular associated concept, the stronger the link between the two.

1B) The stronger the applicability of an associated concept to a particular core competence's needs, the stronger the link between the two.

2A) A core competence and an associated concept that share a future goal that is specific rather than general in nature will develop a strong link.

2B) A core competence and an associated concept that share a history, when the associated concept either sustains the link during dynamic periods or proactively updates it, will develop a strong link.

A link's characteristics contain a core competence's particular need and the focal associated concept's applicability to meet that need. If the characteristics of both the core competence and the focal associated concept are optimized to each other, then the associated concept's influence on the core competence is maximized. If the characteristics of only either the core competence or the focal associated concept are optimized and the characteristics of the other are neglected, or if both are neglected, the influence will be a misuse and accordingly sub-optimal. Such sub-optimal influences may draw resources from other company investments, weakening the core competence's development and eventually compromising the company's future success. Thus, these two aspects, need and applicability, are exclusive and are mutually reinforce the core competence link: if one is missing, a quasi-link may be established. For example, a competence improvement may become linked to a core 
competence, but unless the latter is in need of the improvement, the link will be superficial, with no actual improvements taking place. In the worst case, the corporate top management team may assume that the link is established, that the competence is influencing the core competence. Accordingly, they will continue to develop and nurture the competence, in expectation of ongoing core competence improvement. In fact, superficial links may hinder the future development of both a core competence and an associated concept, since the resources devoted to such links could potentially be better used elsewhere.

The time continuum concept introduced here implies a situation in which a core competence and an associated concept are linked, either by a shared history in which the latter has influenced the former, or by a shared specific future goal, implying an upcoming similar influence. The shared history involves a previous matching between the core competence's need and the associated concept's applicability to meet part or all of that need. The "previous matching" draws on the up-side notions of path dependency [6]. The opposite of what we call superficial links are invisible links. These exist when a core competence and any of the associated concepts share a history and/or a specific future goal; at the same time, this sharing is overlooked and not made visible. The reason for detecting and exposing invisible links is that acknowledging their existence enables managerial action, to strengthen and manage the links to boost core competence development.

\section{IMPLICATIONS}

The discussions presented here suggest that our understanding of core competence should advance beyond mere identification. The paper introduces a new core competence domain for researchers and practitioners alike: not only is the present condition of the core competence concept and the associated concepts' characteristics and links important, but so are their history and future, which implies taking a more holistic approach to core competence issues.

The proposed advance of our understanding of core competence, by going beyond the immediate links between core competence and the associated concepts, opens up the possibility of more comprehensive core competence analysis and management. Top management teams should first direct their attention to the core competence's particular needs, and then to the associated concepts' applicability to meet those needs. The time continuum concept introduced here, referring to shared history and specific future goals, builds our understanding of the link between the concepts, to the ultimate benefit of core competence management.

\section{REFERENCES}

[1] W. Bogner, H. Thomas, and J. Mcgee, "Competence and competitive advantage: Towards a dynamic model," British Journal of Management, vol. 10, pp. 275-290, 1999.

[2] D. Collis and C. Montgomery, Corporate Strategy: A Resource-based Approach, 2 ed. New York: McGraw-Hill/Irwin, 2005.

[3] Y. Wang, H.-P. Lo, and Y. Yang, "The constituents of core competencies and firm performance: Evidence from high-technology firms in china," Journal of Engineering and Technology Management, vol. 21, pp. 249-280, 2004.

[4] U. Ljungquist, "Core competency beyond identification: Presentation of a model," Management Decision, vol. 45, pp. 393-402, 2007.

[5] U. Ljungquist, "Specification of core competence and associated components: A proposed model and a case illustration," European Business Review, vol. 20, pp. 73-90, 2008.

[6] D. Leonard-Barton, "Core capabilities and core rigidities: A paradox in managing new product development," Strategic Management Journal, vol. 13, pp. 111-126, 1992.

[7] D. Lei, M. Hitt, and R. Bettis, "Dynamic core competences through meta-learning and strategic context," Journal of Management, vol. 22, pp. 549-569, 1996.

[8] J. T. Mahoney and R. J. Pandian, "The resourcebased view within the conversation of strategic management," Strategic Management Journal, vol. 13, pp. 363-380, 1992.

[9] R. Nelson and S. Winter, An Evolutionary Theory of Economic Change. Cambridge: Belknap Press, 1982.

[10] C. M. Christensen, The Innovators Dilemma: When New Technologies Cause Great Firms to Fail. Boston, Massachusetts: Harvard Business School Press, 1997.

[11] K. B. Lindkvist, "Mistrust and lack of market innovation: A case study of loss of competitiveness in a seafood industry," European Urban and Regional Studies, vol. 17, pp. 31-43, 2010.

[12] P. Milgrom and J. Roberts, Economics, Organizations and Management. Englewood Cliffs, N.J.: Prentice-Hall, 1992. 
[13] M. Javidan, "Core competence: What does it mean in practice?," Long Range Planning, vol. 31, pp. 60-71, Feb 1998.

[14] C. Eden and F. Ackermann, "Mapping distinctive competencies: A systemic approach," Journal of the Operational Research Society, vol. 51, pp. 12-21, 2000.

[15] C. K. Prahalad and G. Hamel, "The core competence of the corporation," Harvard Business Review, vol. 68, pp. 79-92, 1990.

[16] G. Hamel and C. K. Prahalad, Competing for the Future. Boston: Harvard Business School Press, 1994.

[17] T. Hafsi and H. Thomas, "The field of strategy: In search of a walking stick," European Management Journal, vol. 23, pp. 507-519, 2005.

[18] E. Danneels, "The dynamics of product innovation and firm competences," Strategic Management Journal, vol. 23, pp. 1095-1121, 2002.

[19] R. Grant, "Toward a knowledge-based theory of the firm," Strategic Management Journal, vol. 17, pp. 109-122, 1996.

[20] R. Sanchez, "Understanding competence-based management: Identifying and managing five modes of competence," Journal of Business Research, vol. 57, pp. 518-532, 2004.

[21] R. Amit and P. Shoemaker, "Strategic assets and organization rents," Strategic Management Journal, vol. 14, pp. 33-46, 1993.

[22] G. Stalk, P. Evans, and L. Shulman, "Competing on capabilities," Harvard Business Review, vol. 70, pp. 26-32, 1992.

[23] K. Eisenhardt and J. Martin, "Dynamic capabilities: What are they?," Strategic Management Journal, vol. 21, pp. 1105-1121, 2000.

[24] C. Helfat and M. Peteraf, "The dynamic resource-based view: Capability lifecycles," Strategic Management Journal, vol. 24, pp. 9971010, 2003.

[25] D. J. Teece, G. Pisano, and A. Shuen, "Dynamic capabilities and strategic management," Strategic Management Journal, vol. 18, pp. 509-533, 1997.

[26] D. Collis, "A resource-based analysis of global competition: The case of the bearings industry," Strategic Management Journal, vol. 12, pp. 4968, 1991.

[27] R. Grant, "The resource-based theory of competitive advantage: Implications for strategy formulation," California Management Review, vol. 33, pp. 114-136, 1991.
[28] J. Barney, "Firm resources and sustained competitive advantage," Journal of Management, vol. 17, pp. 99-120, 1991.

[29] I. Dierickx and K. Cool, "Asset stock accumulation and sustainability of competitive advantage," Management Science, vol. 35, pp. 1504-1511, 1989.

[30] S. Gupta, A. Woodside, C. Dubelaar, and D. Bradmore, "Diffusing knowledge-based core competencies for leveraging innovation strategies: Modelling outsourcing to knowledge process organizations (KPOs) in pharmaceutical networks," Industrial Marketing Management, vol. 38, pp. 219-219, 2009.

[31] N. Petts, "Building growth on core competences: A practical approach," Long Range Planning, vol. 30 , pp. 551-561, 1997.

[32] D. Clark, "Implementation issues in core competence strategy making," Strategic Change, vol. 9, pp. 115-127, 2000. 